\title{
IncRNA CCAT2 promotes radiotherapy resistance for human esophageal carcinoma cells via the miR-145/p70S6K1 and p53 pathway
}

\author{
MING WANG $^{1}$, LIANG WANG ${ }^{2}$, XIANG HE $^{3}$, JINHUA ZHANG $^{4}$, \\ ZHONGCHENG ZHU ${ }^{1}$, MINGYUN ZHANG ${ }^{1}$ and XINGDE $\mathrm{LI}^{2}$
}

\begin{abstract}
Departments of ${ }^{1}$ Radiation Therapy, ${ }^{2}$ Digestive Endoscopy and ${ }^{3} \mathrm{CT}$ Diagnosis, Cangzhou Central Hospital, Cangzhou, Hebei 061001; ${ }^{4}$ Department of Pediatrics, Mengcun County Hospital, Cangzhou, Hebei 061400, P.R. China
\end{abstract}

Received June 14, 2019; Accepted September 9, 2019

DOI: 10.3892/ijo.2019.4929

\begin{abstract}
The long non-coding RNA colon cancer-associated transcript 2 (CCAT2) is abnormally expressed in various types of malignant tumor tissues and considered to be an oncogene, including for esophageal cancer (EC). Radiotherapy is an important and widely used cancer treatment. However, some patients with EC do not respond to radiotherapy. This study was designed to investigate effects of CCAT2 expression on radiotherapy dynamics for EC cells and to explore underlying molecular mechanisms. Reverse transcription-quantitative PCR was used to measure CCAT2 expression in EC tissues, normal esophageal mucosa, EC cells and normal human esophageal epithelial cells. TUNEL assays were used to assess the effect of CCAT2 on X-ray-induced apoptosis of EC cells. Protein expression was detected by western blot. CCAT2 was highly expressed in EC tissues and EC cells, and was negatively associated with radiotherapy efficacy in patients with EC. In vitro, knockdown of CCAT2 enhanced radiosensitivity of EC cells and promoted apoptosis by increasing $\mathrm{Bax} / \mathrm{Bcl} 2$ and active-caspase 3/caspase 3 following X-ray treatment. In addition, CCAT2 negatively regulated miR-145 and P70 ribosomal protein S6 kinase 1 (p70S6K1) expression, and inhibited phosphorylation of Akt, ERK and p70S6K1 in EC cells. After $\mathrm{X}$-ray treatment, CCAT2 negatively regulated protein levels of p53, P21 and c-Myc. These results showed that CCAT2 promoted the radiotherapy resistance of EC cells via negative regulation of the miR-145/p70S6K1 and the p53 signaling pathways and associated elements may be potential targets for improving the sensitivity of EC radiotherapy.
\end{abstract}

Correspondence to: Professor Ming Wang, Department of Radiation Therapy, Cangzhou Central Hospital, 16 Xinhua West Road, Cangzhou, Hebei 061001, P.R. China

E-mail: wangmdy@126.com

Key words: long non-coding RNA colon cancer-associated transcript 2, esophageal carcinoma, radiotherapy, apoptosis

\section{Introduction}

Esophageal cancer (EC) is the eighth-ranked cancer of incidence worldwide and the sixth leading cause of cancer-related deaths in $2012(1,2)$. China is the country with the highest incidence and mortality rates from EC globally, with a 5-year overall survival rate $<30 \%$ (3). Most patients with EC are in advanced stages of the disease upon first diagnosis and outcomes for surgical treatment are correspondingly very poor. Therefore, concurrent chemoradiotherapy has become the standard treatment for advanced localized EC, but treatment outcomes still remain poor (4). In recent years, there has been a rapid development in diagnosis and treatment of $\mathrm{EC}$, and although the therapeutic outcomes are better than before, certain EC patients still have local recurrences of tumors and metastasis after treatment $(5,6)$. Such cases exemplify why radiotherapy resistance is considered one of the major predictive factors for poor prognosis and poor outcomes for EC patients (7). Therefore, it is necessary to find new markers that help to accurately predict radiotherapy resistance, so that novel detection targets and treatment methods for EC can be developed and tested.

Long non-coding RNAs (lncRNAs) play an important role in the development of various cancers, and have become a hot topic for tumor research due to tumor tissue specificity and the potential application in tumor diagnosis and treatment outcome prediction $(8,9)$. IncRNAs are a type of RNA that is $>200$ bp in length, lacks or has only a minor portion of an open reading frame, which does not encode a protein, is usually composed of multiple exons spliced together, is transcribed by RNA polymerase II, and has a histone modifier similar to the encoded protein $(10,11)$. An increasing number of lncRNAs have been found to be closely associated with the development of tumors in recent years $(10,11)$, and studies have indicated that lncRNAs can be used as promoters of development and progression for certain types of tumors $(12,13)$.

Colon cancer-associated transcript 2 (CCAT2), a lncRNA, received its name when it was first discovered in colorectal cancer (14). Thereafter, CCAT2 was confirmed to be abnormally expressed in various other tumor types, including breast cancer, ovarian cancer, gastric cancer, non-small cell lung cancer, cervical cancer and esophageal squamous cell 
carcinoma (15). Additional previous studies have indicated that CCAT2 is highly expressed in tumor tissues of esophageal squamous cell carcinoma and is associated with poor patient prognosis $(16,17)$. Although few studies on the relationship between CCAT2 and radiotherapy resistance exist, previous research has confirmed that CCAT2 can inhibit the expression of miR-145 in cancer cells (18), and confirmed that the miR-145/P53 pathway is associated with radiotherapy resistance in cancer cells (19). In addition, previous studies have found that P70 ribosomal protein S6 kinase 1 (p70S6K1), an important effector protein downstream of the apoptosis-associates Akt/ERK signaling pathway, is a target gene of miR-145 (20). Therefore, our study was designed to investigate effects of CCAT2 expression on radiotherapy treatments for EC cells and to examine whether CCAT2 promoted radiotherapy resistance in EC cells via the miR-145/p70S6K1 and the p53 signaling pathways.

\section{Materials and methods}

Tissue and ethics statement. A total of $60 \mathrm{EC}$ tissue and 21 healthy esophageal mucosa were sampled for biopsy between June 2016 and June 2018 at Cangzhou Central Hospital Hospital. The EC tissues included 38 male and 22 female patients with a mean age at diagnosis of $60.46 \pm 9.24$ years and the healthy esophageal mucosa samples included 12 male and 9 female patients with a mean age of $59.62 \pm 4.72$ years. Inclusion criteria were based on the following: i) No anticancer treatment before tissue acquisition; ii) no other malignant tumors or chronic infectious diseases present; iii) normal tissue samples were confirmed by lack of any lesions in tissues; and iv) completion of clinical information, such as age, gender, medical history and a treatment plan. Exclusion criteria included: i) Failure to complete 3 years of follow-up; ii) death due to other diseases or accidents; iii) pregnancy, lactating and drug abusers; and iv) withdrawal from other types of medical treatments, such as participate in and withdraw from other clinical trials for drugs or biotherapies). All EC patients received radiation therapy after surgery. According to the patient's specific conditions, the prescription dose was 50-66 Gy. The divided dose was $2 \mathrm{~Gy} / \mathrm{day}$, once a day, 5 times a week, 6-7 weeks in total. Patients were treated with the Varian 23EX and 120-leaf MLC 600C/D linear accelerators. In addition, all patients or their representatives signed informed consent documents. The Ethics Committee of the Cangzhou Central Hospital reviewed, approved and supervised all aspects of the study design and experiments.

Reagents. Lipofectamine 2000 (1668019), Lab-Tek Chambered Coverglass (LOT1228622), the TUNEL assay kit (C10625), DAPI (D21490), DMEM (61870044) and fetal bovine serum (FBS; 10437028) were purchased from Thermo Fisher Scientific, Inc. We used the PrimeScript RT reagent Kit with gDNA Eraser (RR047B; Takara Bio, Inc.), GoTaq ${ }^{\circledR}$ qPCR Master Mix (A6002; Promega Corporation), and the BCA Protein Assay kit (ab102536) and all antibodies were purchased from Abcam.

Cell culture, treatment and transfection. HEEC, TE-1, TE-3, ECA109, KYSE410, and KYSE520 cell lines were purchased from The Cell Bank of Type Culture Collection of the
Chinese Academy of Sciences. TIE-3 cells overexpressing CCAT2 were established by Genomeditech Co., Ltd. All cells were cultured in DMEM plus $10 \% \mathrm{FBS}$ at $37^{\circ} \mathrm{C}$ with $5 \% \mathrm{CO}_{2}$. For the X-ray treatment, $0.6-0.8 \times 10^{6}$ cells were seeded in Lab-Tek Chambered Coverglass or $1.5-2.0 \times 10^{6}$ cells were seeded in 6-well plates and cultured for $24 \mathrm{~h}$. Then, cells were exposed to 4 Gy irradiation for $24 \mathrm{~h}$ after transfection. We used LncBASE v.2 (http://carolina.imis.athena-innovation.gr/diana_tools/web/index.php? $r=\operatorname{lncbasev} 2 \% 2$ Findex) to analyze the sequences of CCAT2 and miR-145.

miR-negative control (NC; 5'-AGAUCGACCCAGGCC GUAUAUGU-3'), miR-145-mimic (5'-GUCCAGUUUUCC CAGGAAUCCCU-3') and miR-145-inhibitor (5'-CAGGUC AAAAGGGUCCUUAGGGA-3'), as well as small interfering RNA (si)-NC (forward, 5'-ACAUCAUAGUCGAACUUU ATT-3' and reverse, 5'GAAAAGGACACUAUGCGGCTT-3'), si-P53 (forward, 5'-UGGAUUUGUACCAUUCUUCUG-3' and reverse, 5'-GAAGAAUGGUACAAAUCCAAG-3') and si-CCAT2 (forward, 5'-ACUCAUUGGUUCCUUUAAGGG-3' and reverse 5'-CUUAAAGGAACCAAUGAGUCC-3') at $50 \mathrm{nmol} / 1$ were transfected into $2.5 \times 10^{6} \mathrm{TE}-3$ and ECA-109 using Lipofectamine 2000 according to the manufacturer's protocols. For wild type or mutated versions of the 3'-UTR of MALAT1 were cloned into pisCHECK2 (cat. no. 97157; Addgene, Inc.), and then began transfection into cells as miRNA. After $72 \mathrm{~h}$, expression was determined by reverse transcription-quantitative (RT-q) PCR or western blot.

$R T-q P C R$. Levels of CCAT2, miR-145 and p70S6K1 mRNA were detected by RT-qPCR as previously described (21). Briefly, TRIzol ${ }^{\circledR}$ (Invitrogen; Thermo Fisher Scientific, Inc.) was used to extract total RNA from tissues or cells and RT was performed under the following conditions: $37^{\circ} \mathrm{C}$ for $15 \mathrm{~min}, 85^{\circ} \mathrm{C}$ for $5 \mathrm{sec}$ and hold at $4^{\circ} \mathrm{C}$. qPCR was performed using the following protocol: $95^{\circ} \mathrm{C}$ for $30 \mathrm{sec}$, followed by 40 cycles of $90^{\circ} \mathrm{C}$ for $5 \mathrm{sec}$ and $65^{\circ} \mathrm{C}$ for $30 \mathrm{sec}$. PCR primer sets were as follows: CCAT2 forward (F), 5'-CCCTGGTCAA ATTGCTTAACCT-3' and reverse (R), 5'-TTATTCGTCCCT CTGTTTTATGGAT-3'; miR-145-F, 5'-CCTTGTCCTCAC GGTCCAGT-3' and miR-145-R, 5'-AACCATGACCTCAAG AACAGTATTT-3'; p70S6K1-F, 5'-GGGGCTATGGAAAGG TTTTTCA-3' and p70S6K12-R, 5'-CGTGTCCTTAGCATT CCTCACT-3'; U6-F, 5'-CTCGCTTCGGCAGCACA-3' and U6-R, 5'-AACGCTTCACGAATTTGCGT-3'; and GAPDH-F, 5'-CTCGCCTAGAGTGAGCTCC-3' and GAPDH-R, 5'-AAC TGCTGCGTTGACGGGTATG-3'. The $2^{-\Delta \Delta C q}$ method (22) was used to calculate relative expression levels of genes. GAPDH as a reference gene and in addition we used U6 as a reference gene in miR quantification.

Fluorescence in situ hybridization. A fluorescent probe for binding to the human version of the CCAT2 gene was synthesized by Genomeditech Co., Ltd. Fluorescence levels of in situ hybridization of CCAT2 in different EC cells was determined as described previously (18). We analyzed samples using fluorescence microscopy (magnification, x20) and LAS AF Lite 4.0 image analysis software (Leica Microsystems, Inc.).

Dual-luciferase reporter assay. The Dual-Lucy Assay kit (cat. no. D00100; Beijing Solarbio Science \& Technology Co., 

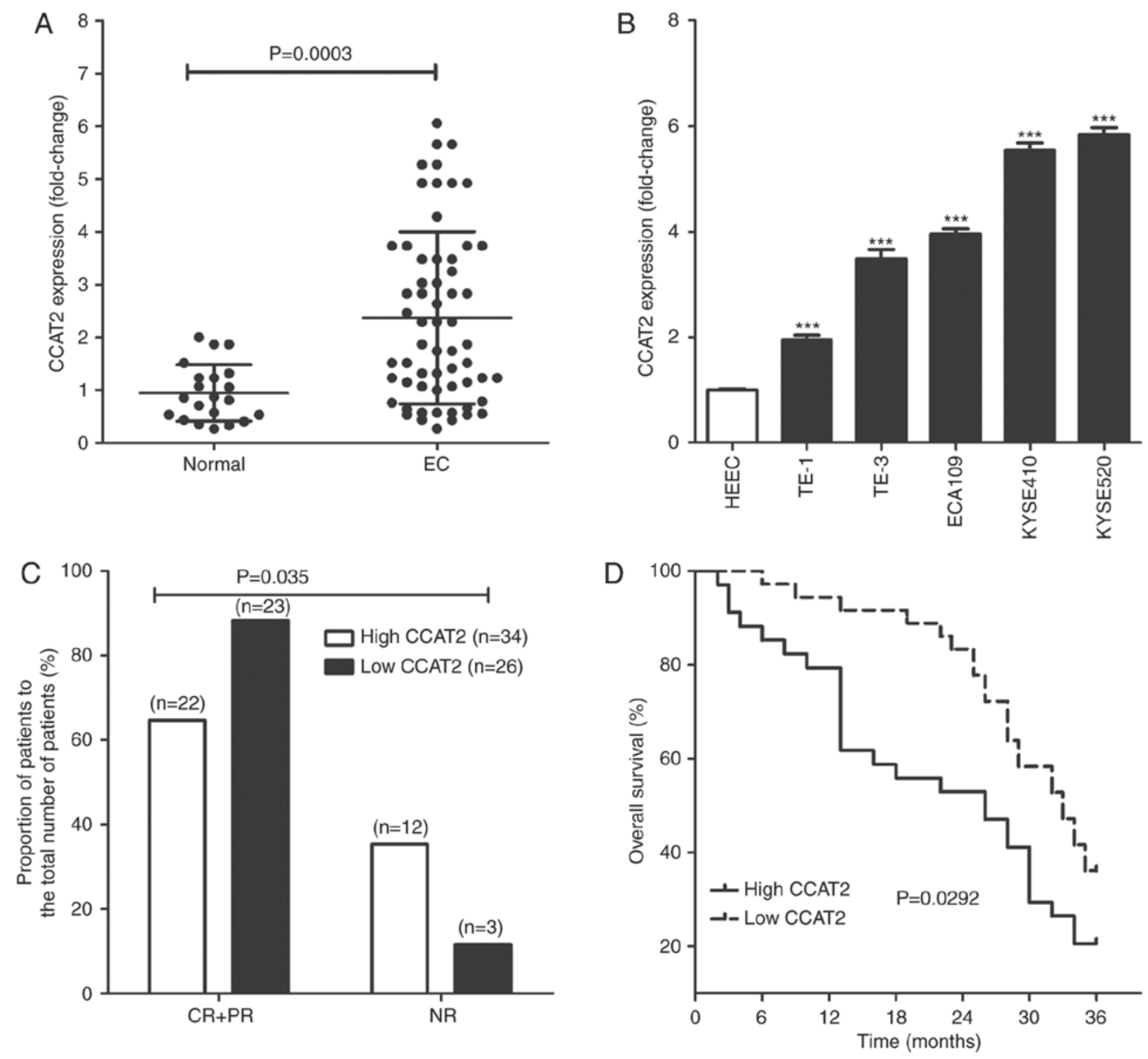

Figure 1. Effect of CCAT2 expression on radiotherapy in patients with EC. (A) Expression of CCAT2 in EC tumor tissues and normal esophageal mucosa. (B) Expression of CCAT2 in HEEC, TE-1, TE-3, ECA109, KYSE410 and KYSE520. ${ }^{* * *} \mathrm{P}<0.001$ vs. HEEC. (C) Effects of CCAT2 expression in EC patients after radiotherapy. (D) Overall survival of patients with EC based on CCAT2 expression. CCAT2, long non-coding RNA colon cancer-associated transcript 2; EC, esophageal cancer; CR, complete response; PR, partial response; NR, no response.

Ltd.) was used to detect luciferase activity following the manufacturer's protocol. Briefly, cells were collected at $48 \mathrm{~h}$ after transfection and lysed for $5 \mathrm{~min}$ on ice before centrifugation $(12,000 \mathrm{x} \mathrm{g}$ for $1 \mathrm{~min}$ at room temperature) to collect the cell supernatant. Five volumes of firefly luciferase reaction solution or Renilla luciferase reaction solution were added to the cell lysate and the enzyme activity was detected. Firefly luciferase activity was normalized to Renilla luciferase activity.

TUNEL assays. We seeded $0.6-0.8 \times 10^{6}$ cells in Lab-Tek Chambered Coverglass and cultured for $24 \mathrm{~h}$. Then, we added DAPI $(5 \mu \mathrm{g} / \mathrm{ml})$ to the culture medium for $5 \mathrm{~min}$ at $37^{\circ} \mathrm{C}$, then removed the medium, washed samples twice with PBS and applied $4 \%$ paraformaldehyde to fix samples at room temperature for $20 \mathrm{~min}$. Cell membranes were penetrated by applying $0.3 \%$ Triton X-100 in PBS for $1 \mathrm{~h}$ at room temperature. Next,
TUNEL test solution (50 $\mu 1)$ was added and samples were incubated in the dark for $60 \mathrm{~min}$ at $37^{\circ} \mathrm{C}$. Products were washed twice with PBS and analyzed using fluorescence microscopy (magnification, $x 20$ ). We have observed $\geq 10$ fields of view per sample and LAS AF Lite 4.0 image analysis software was used to evaluate the data.

Western blotting. The EpiQuik Whole Cell Extraction Kit (cat. no. OP-0003; Amyjet Scientific) to exact the total protein from cells. Levels of Bax (cat. no. ab32503; 1:1,000), Bcl2 (cat. no. ab32124; 1:2,000), caspase 3 (cat. no. ab13847; 1:2,000), active-caspase 3 (cat. no. ab2302; 1:500), p70S6K1 (cat. no. ab9366; 1:1,000), phosphorylated (P)-p70S6K1 (cat. no. ab60948; 1:500), P-ERK (cat. no. ab184699; 1:1,000), ERK (cat. no. ab201015; 1:2,000), P-Akt (cat. no. ab81283; 1:2,000), Akt (cat. no. ab64148; 1:2,000), 

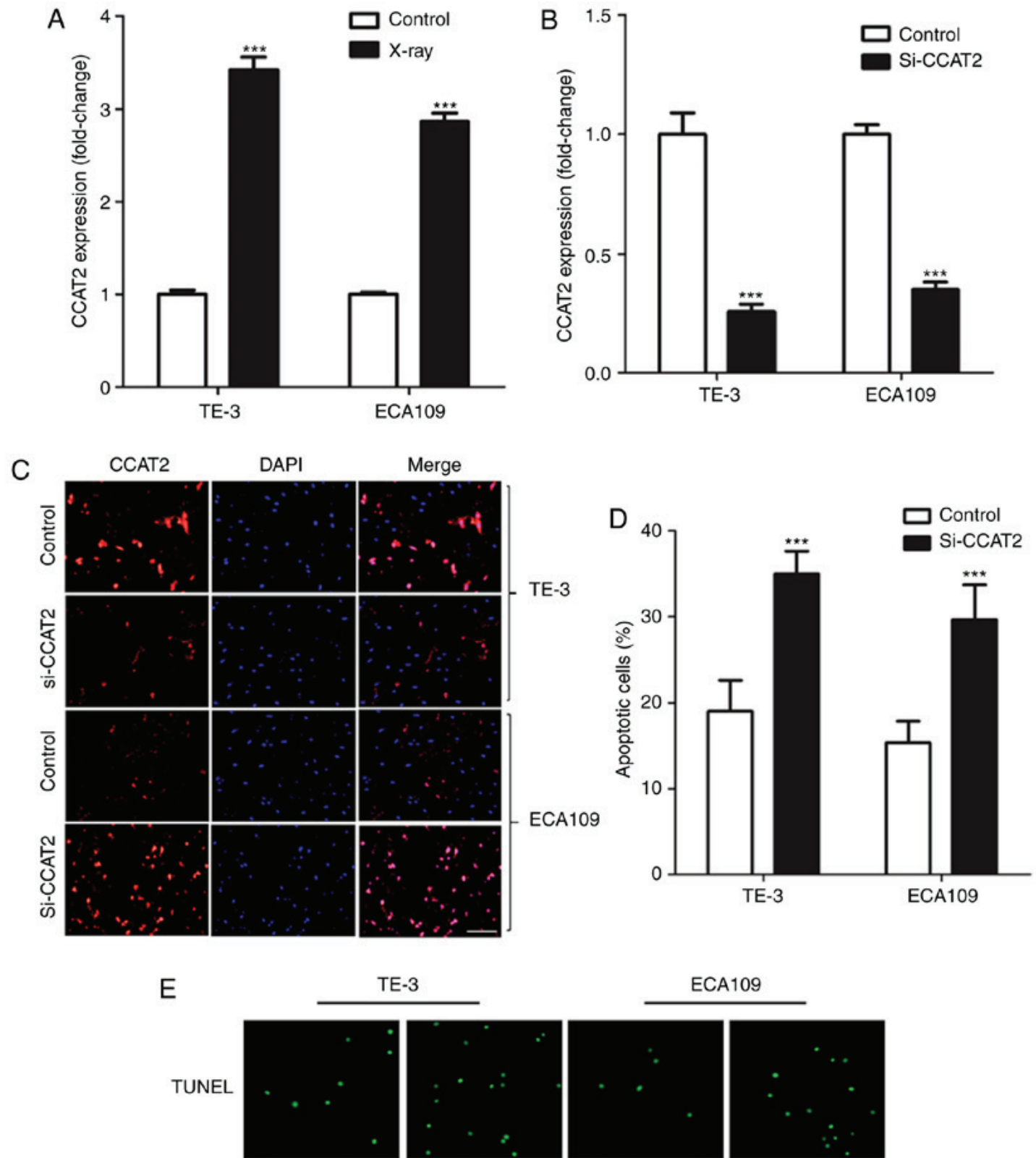

TE-3

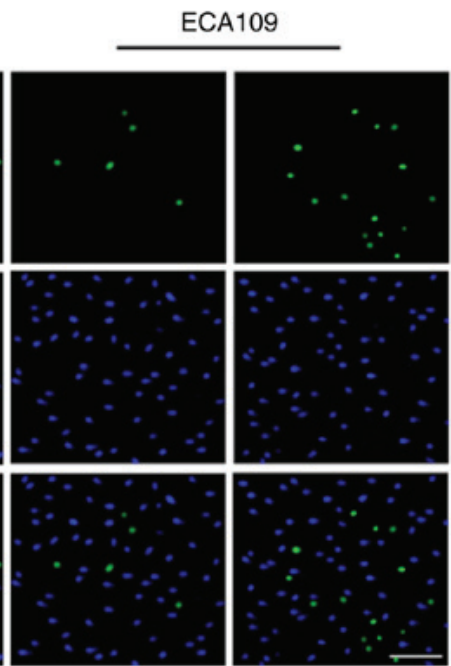

Figure 2. CCAT2 expression affects radiosensitivity of esophageal cancer cells. (A) CCAT2 expression in TE-3 and ECA109 cells with and without X-ray irradiation. CCAT2 expression in TE-3 and ECA109 cells transfected with Si-CCAT2 or control detected by (B) reverse transcription-quantitative PCR and (C) fluorescence in situ hybridization; scale bar, $50 \mu \mathrm{m}$. (D) Quantification of TUNEL assay results and (E) fluorescence images for TE-3 and ECA109 cells transfected with Si-CCAT2 or control; scale bar, $50 \mu \mathrm{m} .{ }^{* * *} \mathrm{P}<0.001$ vs. Control. CCAT2, long non-coding RNA colon cancer-associated transcript 2; Si, small interfering RNA.

p53 (cat. no. ab131442; 1:1,000), P21 (cat. no. ab159520; 1:3,000), c-Myc (cat. no. ab32072; 1:1,000) and GAPDH (cat. no. ab181602; 1:5,000; all from Abcam) protein were detected by western blot as previously described (21). We used
TBST diluted with 5\% skim milk as a blocking solution at room temperature for $1 \mathrm{~h}$. Primary and secondary antibodies (goat anti-rabbit HRP-conjugated IgG; cat. no. ab6721; 1:1,000 or goat anti-mouse HRP-conjugated IgG; cat. no. ab205719; 

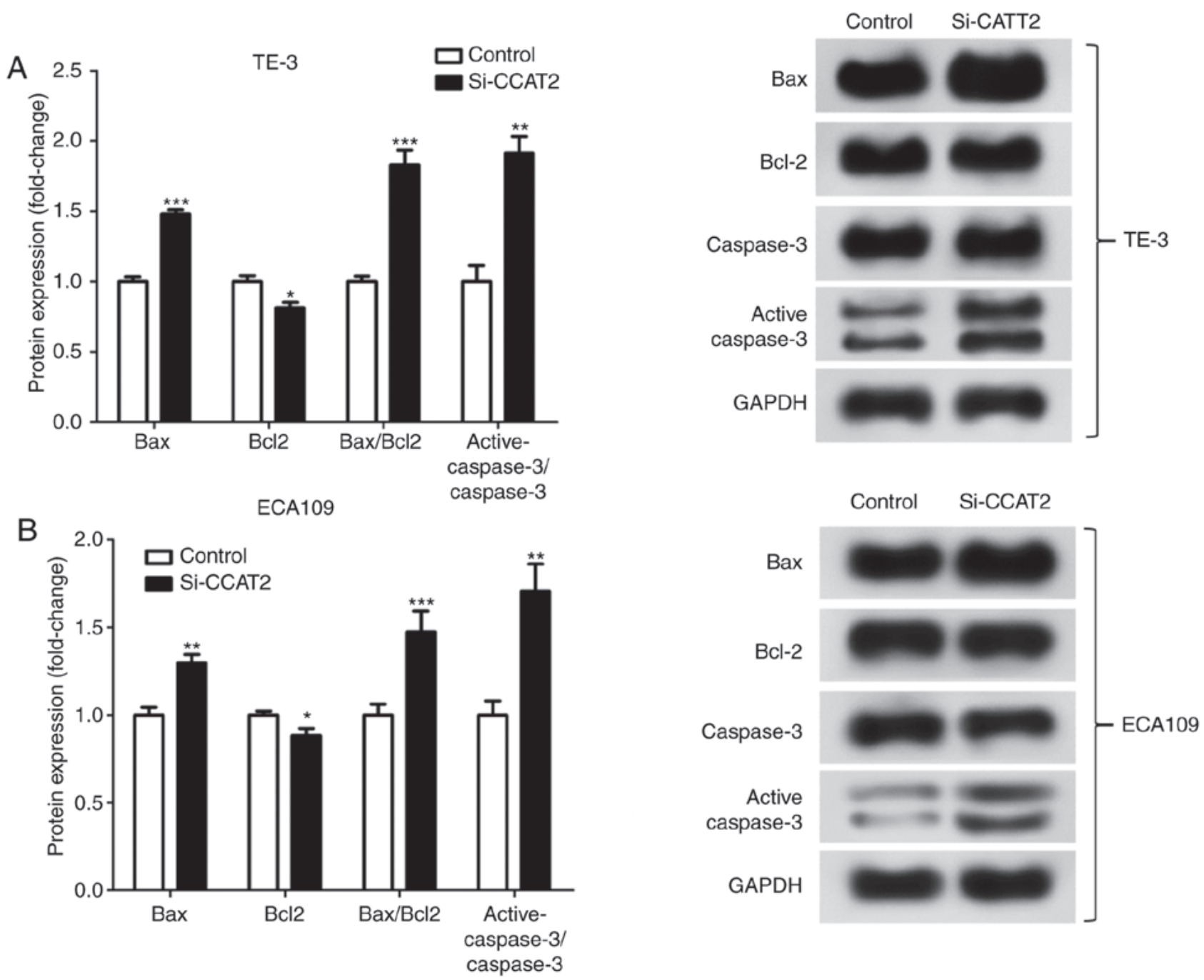

Figure 3. CCAT2 knockdown affects the expression of Bax, Bcl2 and caspase 3 in esophageal cancer cells. Western blot images and quantification of protein expression in esophageal cancer cells transfected with Si-CCAT2 or control following X-ray treatment. ${ }^{*} \mathrm{P}<0.05,{ }^{* * *} \mathrm{P}<0.01$ and ${ }^{* * * *} \mathrm{P}<0.001$ vs. Control. CCAT2, long non-coding RNA colon cancer-associated transcript 2; Si, small interfering RNA.

1:2,000; from Abcam) were diluted with blocking solution and were incubated for 2 or $1 \mathrm{~h}$ at room temperature, respectively. ImageJ (version 1.37; National Institutes of Health) was used to analyze gray values of protein bands and GAPDH was used as the control.

Statistical analysis. Data were analyzed using SPSS 20.0 (IBM Corp.). Data are presented as the mean \pm SD of at least 3 independent experiments. Two treatment groups were compared using unpaired Student's t-test or Chi-square test. Multiple group ( $>2$ ) comparisons were made using one-way ANOVA followed by Duncan's test. Kaplan-Meier analysis was used to generate survival plots and significance was assessed by log-rank test. $\mathrm{P}<0.05$ was considered to indicate a statistically significant difference.

\section{Results}

CCAT2 is associated with radiotherapy efficacy in EC patients. A total of $60 \mathrm{EC}$ tissues and 21 normal esophageal mucosa were obtained and CCAT2 levels were determined. As seen in Fig. 1A, CCAT2 levels were significantly higher in EC tissues compared with normal esophageal mucosa $(\mathrm{P}<0.05)$. The same result was observed in vitro for various cell lines, where CCAT2 was significantly increased in EC cells, including TE-1, TE-3, ECA109, KYSE410 and KYSE520 compared with normal HEECs $(\mathrm{P}<0.05$; Fig. 1B).

EC patients were assigned into two treatment groups based on CCAT2 expression level; namely a high and an low CCAT2 group. Upon conclusion of radiotherapy treatments, patients were evaluated for resultant effects according to Response Evaluation Criteria In Solid Tumor in 2000 (23) and we identified 22 cases of complete response (CR) + partial response (PR) and 12 cases of no response (NR) in the high CCAT2 group. In the low CCAT2 group, we identified 23 cases of $C R+P R$ and 3 cases of NR (Fig. 1C). The 3-year overall survival of EC patients in the low CCAT2 group was significantly longer than for patients with EC in the high CCAT2 group (Fig. 1D).

Knockdown of CCAT2 induces enhanced radiosensitivity of EC cells. Firstly, we found that X-ray treatment significantly increased in CCAT2 expression in EC cells in vitro (Fig. 2A). We knocked down CCAT2 expression using si-CCAT2 (Fig. 2B and C) to study the effect of CCAT2 expression on 

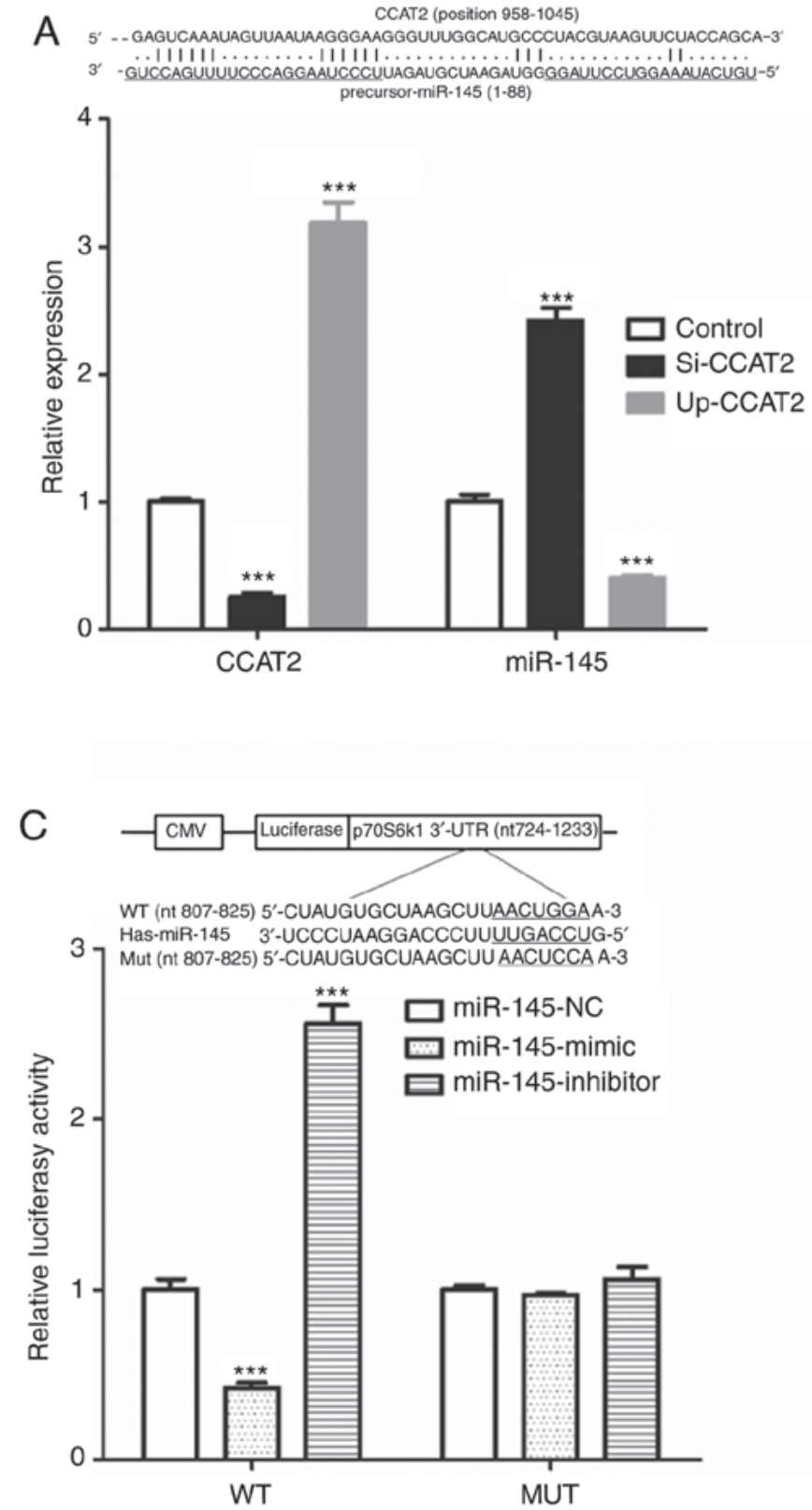
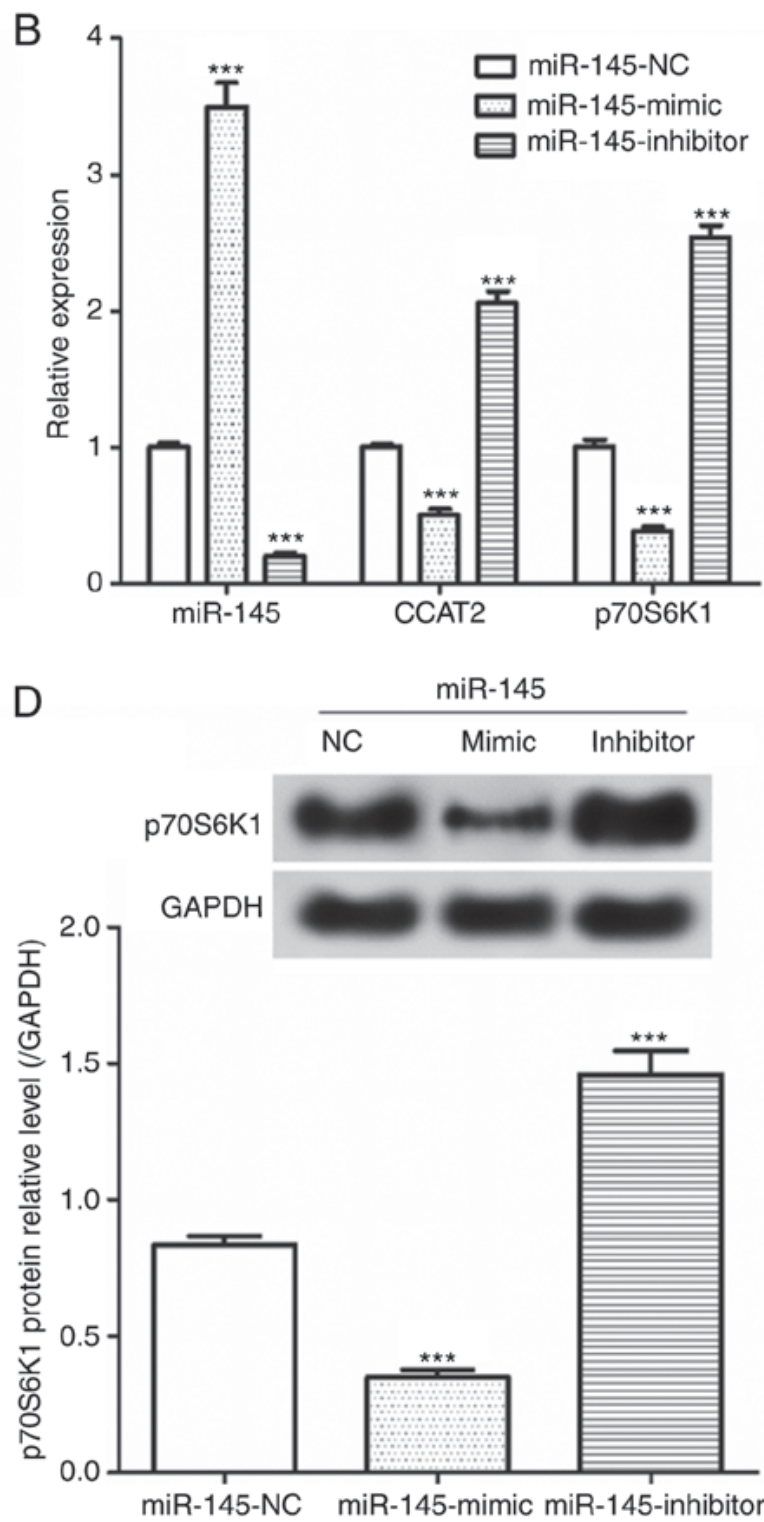

Figure 4. CCAT2 expression effects the miR-145/p70S6K1 signaling pathway in TE-3 cells. (A) Alignment of CCAT2 and miR-145 sequences and expression of CCAT2 and miR-145 following transfection with Si-CCAT2 and Up-CCAT2. ${ }^{* * *} \mathrm{P}<0.001$ vs. Control. (B) Expression of miR-145, CCAT2 and p70S6K1 following transfection with miR-145 mimic, inhibitor or NC. (C) Sequence alignment of miR-145 and p70S6K1 and luciferase activity in WT and MUT groups transfected with miR-145 mimic, inhibitor or NC. (D) p70S6K1 protein expression in cells transfected with miR-145 mimic, inhibitor or NC. ${ }^{* * *} \mathrm{P}<0.001 \mathrm{vs}$. miR-145-NC. CCAT2, long non-coding RNA colon cancer-associated transcript 2; Si, small interfering RNA; Up, overexpression vector; NC, negative control; WT, wild type; MUT, mutant; p70S6K1, P70 ribosomal protein S6 kinase 1.

radiosensitivity of EC cells and found that knockdown of CCAT2 significantly enhanced apoptosis of EC cells after X-ray treatment (Fig. 2D and E). Moreover, we found that knockdown of CCAT2 significantly increased $\mathrm{Bax} / \mathrm{Bcl} 2$ protein expression and significantly increased the active-caspase 3/caspase 3 ratio in EC cells after X-ray treatment (Fig. 3).

CCAT2 negatively regulates the $\mathrm{miR}-145 / \mathrm{p} 70 \mathrm{~S} 6 \mathrm{~K} 1$ and the Akt/ERK/p70S6K1 signaling pathways. As presented in Fig. 4A, si-CCAT2 was significantly reduced CCAT2 expression and significantly increased miR-145 expression. Furthermore, we showed that transfection with Up-CCAT2 significantly increased CCAT2 expression and significantly decreased miR-145 expression. Additionally, miR-145-mimics significantly increased in miR-145 expression and significantly decreased CCAT2 and p72S6K1 mRNA expression (Fig. 4B). miR-145-inhibitor transfection resulted in a significant decrease in miR-145 levels and significant increases CCAT2 and p72S6K1 mRNA expression. Results from the dual luciferase reporter assay suggested that in the WT, miR-145-mimic transfection significantly decreased luciferase activity and miR-145-inhibitor transfection significantly increased luciferase activity compared with the miR-145-NC transfected cells (Fig. 4C). However, miR-145-mimic and miR-145-inhibitor did not affect the luciferase activity in the MUT group. As seen in Fig. 4D, transfection with miR-145-mimic significantly 

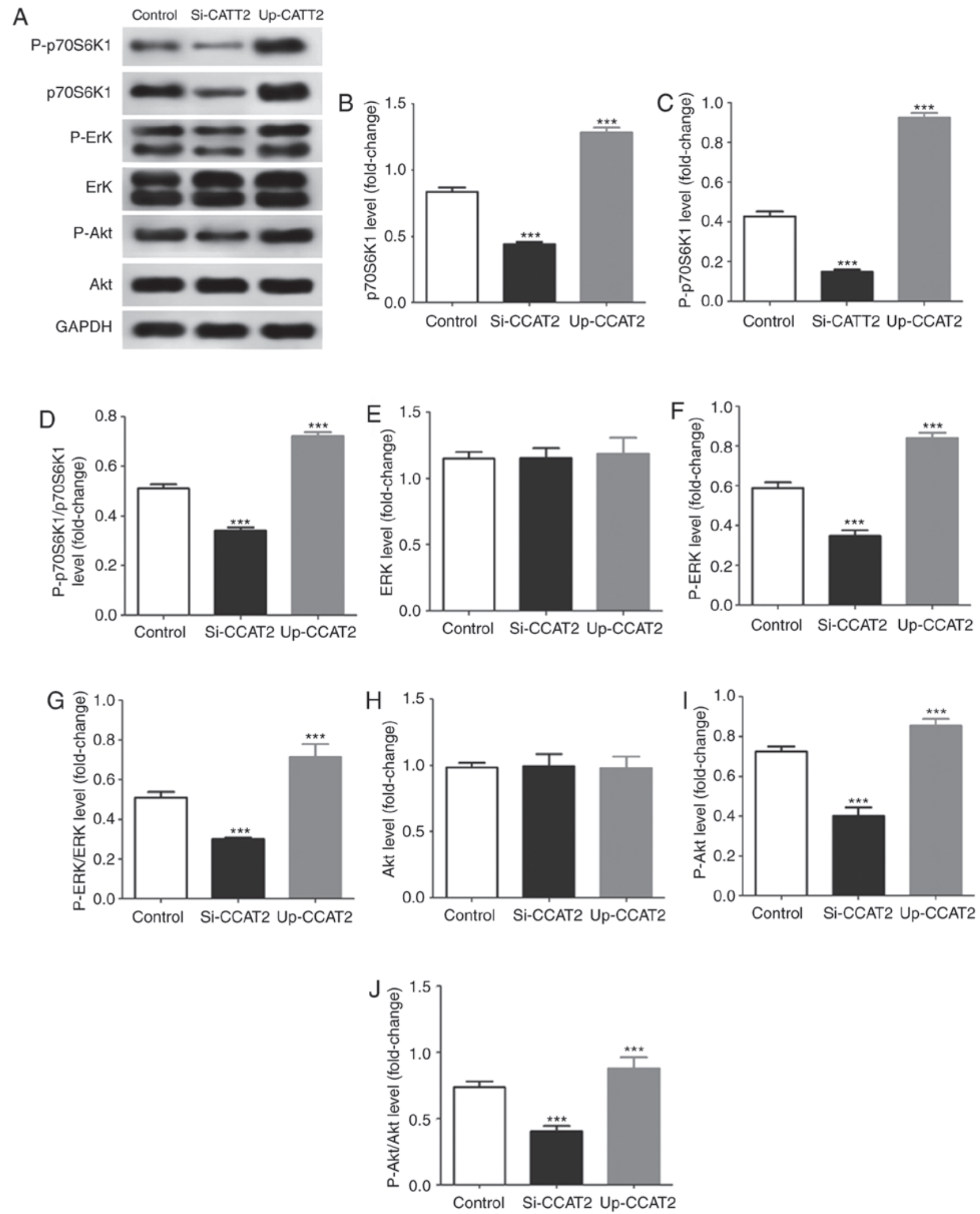

Figure 5. CCAT2 expression affects the Akt/ERK/p70S6K1 signaling pathway in TE-3 cells after X-ray treatment. (A) Western blot images and quantified levels of (B) p70S6K1, (C) P-p70S6K1, (D) P-ERK/ERK, (E) P-p70S6K1/p70S6K1, (F) ERK, (G) P-ERK, (H) Akt, (I) P-Akt and (J) P-Akt/Akt in cells transfected with Si-CCAT2, Up-CCAT2 or a control. ${ }^{* * *} \mathrm{P}<0.001$ vs. Control. CCAT2, long non-coding RNA colon cancer-associated transcript 2; Si, small interfering RNA; Up, overexpression vector; p70S6K1, P70 ribosomal protein S6 kinase 1; P-, phosphorylated.

decreased p70S6K1 protein expression and miR-145-inhibitor transfection significantly increased p70S6K1 protein expression compared with the miR-145-NC transfected cells.
In addition, in TE-3 cells exposed to X-ray irradiation, we found that knockdown of CCAT2 significantly decreased levels of p70S6K1, P-p70S6K1, P-ERK and P-Akt and CCAT2 

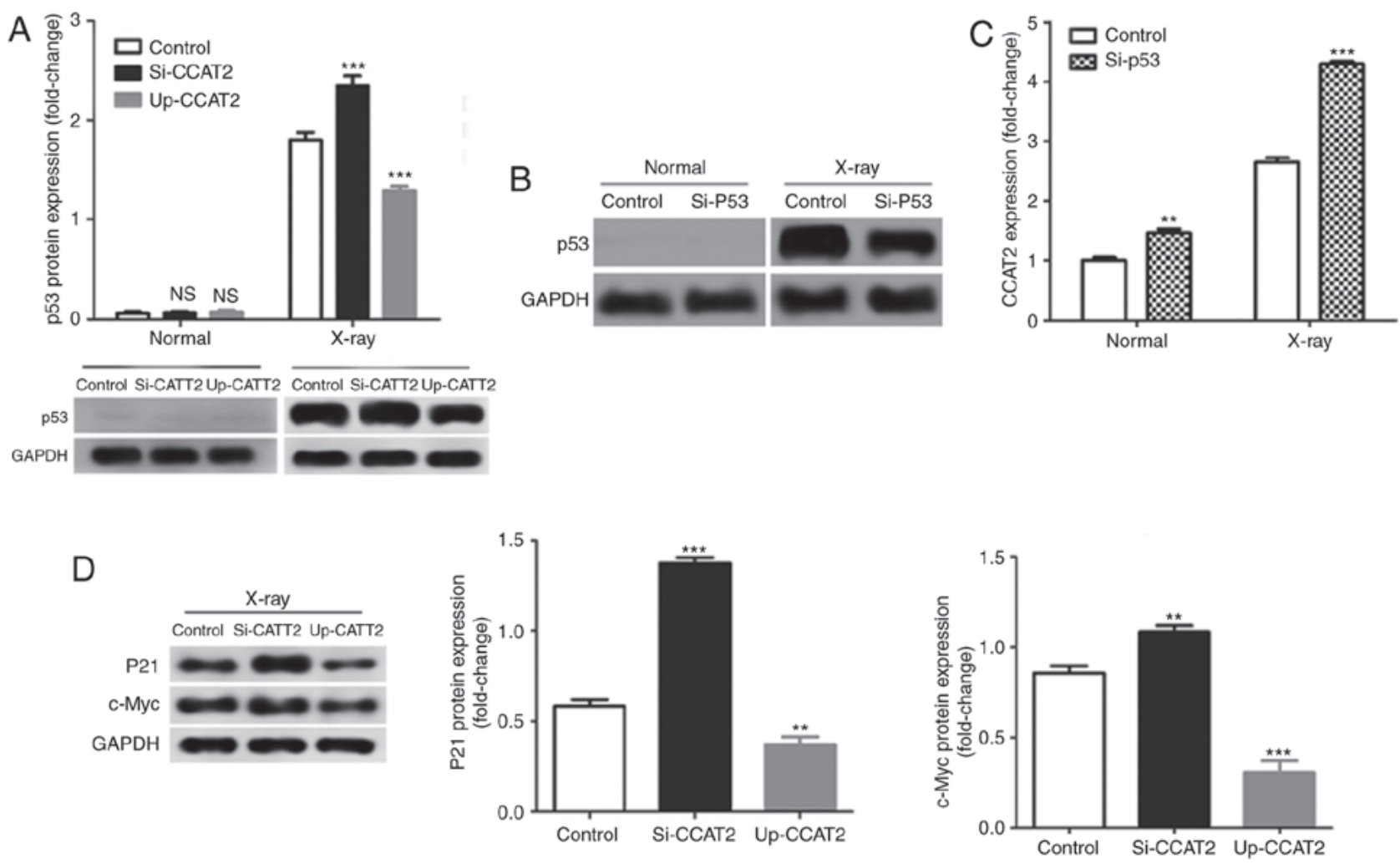

Figure 6. CCAT2 expression affects the p53 signaling pathway in TE-3 cells. (A) p53 protein expression TE-3 cells transfected with Si-CCAT2, Up-CCAT2 or a control with or without X-ray treatment. (B) p53 protein expression after knockdown with Si-p53. (C) CCAT2 expression in TE-3 cells transfected with Si-p53 or a control with or without X-ray treatment. (D) Western blot images and quantification of p21 and c-Myc expression in TE-3 cells transfected with Si-CCAT2, Up-CCAT2 or a control after X-ray treatment. ${ }^{* * *} \mathrm{P}<0.001$ vs. Control. CCAT2, long non-coding RNA colon cancer-associated transcript 2; Si, small interfering RNA; Up, overexpression vector.

overexpression significantly increased levels of p70S6K1, P-p70S6K1, P-ERK and P-Akt (Fig. 5). Results further indicated that knockdown of CCAT2 significantly decreased in phosphorylation of p70S6K1, ERK and Akt, and overexpression significantly increased activation of these proteins.

CCAT2 negatively regulates the p53 signaling pathway. Levels of CCAT2 expression did not significantly affect p53 expression in TE-3 cells without X-ray treatment; however, knockdown of CCAT2 significantly increased and overexpression significantly decreased p53 protein expression in TE-3 cells after X-ray treatment compared with the control (Fig. 6A). Next, we knocked down p53 expression by transfection with si-p53; a decrease in protein expression is only visible in the X-ray treated cells due to the absence of protein expression in the non-X-ray exposed cells (Fig. 6B). Knockdown of p53 significantly increased in CCAT2 expression in TE-3 cells with or without X-ray treatment compared with the control (Fig. 6C). In addition, knockdown of CCAT2 significantly increased and overexpression of CCAT2 significantly decreased levels of p21 and c-Myc protein expression in TE-3 cells after X-ray treatment compared with the control (Fig. 6D).

\section{Discussion}

In the present study, we found that CCAT2 was highly expressed in EC tissues and cells, which was consistent with available literature $(16,17)$. On further analysis of the association between CCAT2 expression and radiotherapy efficacy in patients with EC, we found that EC patients with low levels of CCAT2 had better efficacy and outcomes from radiotherapy, and longer overall survival times. Tumor staging and other treatment options for EC patients may have additional effects on the efficacy of radiotherapy and overall survival times and require further analysis in the future. However, our results suggested that CCAT2 may be involved in the dynamics of sensitivity of EC patients to radiotherapy.

Using in vitro experiments, we found that $\mathrm{X}$-ray treatment increased levels of CCAT2 in EC cells and knockdown of CCAT2 promoted X-ray-induced apoptosis of EC cells. Although no prior research has reported associations between CCAT2 expression and EC cell apoptosis, it was reported that overexpression of CCAT2 inhibits apoptosis of cervical cancer (24) and hepatocellular carcinoma cells (25). At present, neoadjuvant chemoradiotherapy or chemotherapy alone have become the standards for treatment of localized developing and advanced EC $(26,27)$. Accordingly, radiotherapy has played a key role in the treatment of EC patients and has been rapidly developed as a course for treatment in recent decades (28). As radiotherapy is an important treatment for EC patients, radiotherapy resistance has recently attracted more attention. Previous studies indicated that radiotherapy can induce tumor cell apoptosis and that sensitivity of tumors to radiotherapy is consistent with sensitivities of tumor cells to apoptosis $(29,30)$. Our results suggested that CCAT2 enhanced the resistance of EC cells to radiotherapy by inhibiting apoptosis. 
Although studies that established a link between CCAT2 expression and tumor cell radiotherapy sensitivity are rare, potential molecular mechanisms can be hypothesized. Firstly, previous studies indicated CCAT2 inhibits expression of miR-145 in tumor cells (18) and miR-145 enhances radiosensitivity of cervical cancer (31), prostate cancer (32) and hepatocellular carcinoma cells (33). Our results also indicated that CCAT2 and miR-145 inhibited each other in EC cells. Moreover, our results indicated that miR-145 inhibited p70S6K1 protein expression. Previous studies indicated that the PI3K/Akt signaling pathway and downstream kinase p70S6K1 are important in mediating cell proliferation, differentiation and apoptosis $(34,35)$. Activation of PI3K is a primary signal for inhibition of apoptosis, and PI3K induces Akt activation, which in turn activates p70S6K1 ultimately resulting in the inhibition of cell apoptosis $(34,35)$. Our results indicated that CCAT2 decreased phosphorylation of Akt, ERK and p70S6K1 in EC cells. Therefore, indicating that CCAT2 enhanced the resistance of EC cells to radiotherapy by inhibiting apoptosis via inhibiting the miR-145/p70S6K1 signaling pathway and by activating the Akt/ERK/p70S6K1 signaling pathway.

Radiotherapy is based on the energy transmitted by radiation destroying the chromosome of the cell causing DNA damage in tumor cells, stopping cell growth by inducing apoptosis and halting proliferation of tumor cells $(36,37)$. The P53 signaling pathway plays an important role in some of the aspects related to cellular DNA damage, repair, and apoptosis $(38,39)$. We found that CCAT2 downregulated expression of p53, p21 and c-Myc proteins. When DNA damage occurs in cells, elevated levels of p53 induce a variety of downstream events, including cell cycle arrest, DNA repair or differentiation, and apoptosis $(38,39)$. p53 activates the expression of $\mathrm{p} 21$, which induces cell cycle inhibition and repairs of damaged DNA. Further, if DNA damaged cannot be repaired smoothly, p53 regulates apoptosis $(40,41)$. In the p53-dependent apoptotic signaling pathway, p21 is indirectly involved in apoptosis through cell cycle arrest, but is not essential for apoptosis $(40,41)$. In addition, studies have indicated that c-Myc regulates the function and activity levels of p21 in association with apoptosis $(42,43)$. Furthermore, it was found that c-Myc does not affect binding of p53 to p21, but that p53 selectively inhibits the activation of $\mathrm{p} 21$, thereby regulating p21 expression beneficial for p53-mediated apoptosis $(42,43)$.

In conclusion, we found that CCAT2 was highly expressed in EC tissues and that it promoted the resistance of radiotherapy treatment in patients with EC and EC cells by decreasing apoptosis via inhibiting the miR-145/p70S6K1 signaling pathway. CCAT2 further inhibited the p53 signaling pathway and induced activation of the Akt/ERK/p70S6K1 signaling pathway. Our findings provided novel information to help further methodological approaches for the management of patients with EC.

\section{Acknowledgements}

Not applicable.

\section{Funding}

This study was supported by The Excellent Going Abroad Experts' Training Program in Hebei Province.

\section{Availability of data and materials}

All data generated or analyzed during the present study are included in this published article.

\section{Authors' contributions}

MW and LW conceived and designed the study. XH, JZ, ZZ, MZ and XL performed the experiments and analyzed the data. MW prepared and revised the manuscript. All authors read and approved the final version of the manuscript.

\section{Ethics approval and consent to participate}

The present study was performed with the approval of the Ethics Committee of Cangzhou Central Hospital. All aspects of the study complied with the Declaration of Helsinki. All participants provided written informed consent.

\section{Patient consent for publication}

Not applicable.

\section{Competing interests}

The authors declare that they have no competing interests.

\section{References}

1. Ferlay J, Soerjomataram I, Dikshit R, Eser S, Mathers C, Rebelo M, Parkin DM, Forman D and Bray F: Cancer incidence and mortality worldwide: Sources, methods and major patterns in GLOBOCAN 2012. Int J Cancer 136: E359-E386, 2015.

2. Torre LA, Bray F, Siegel RL, Ferlay J, Lortet-Tieulent J and Jemal A: Global cancer statistics, 2012. CA Cancer J Clin 65: 87-108, 2015

3. Chen W, Zheng R, Baade PD, Zhang S, Zeng H, Bray F, Jemal A, $\mathrm{Yu}$ XQ and He J: Cancer statistics in China, 2015. CA Cancer J Clin 66: 115-132, 2016.

4. Zheng H, Ren W, Pan X, Zhang Q, Liu B, Liu S, He J and Zhou Z: Role of intravoxel incoherent motion MRI in early assessment of the response of esophageal squamous cell carcinoma to chemoradiotherapy: A pilot study. J Magn Reson Imaging 48: 349-358, 2018.

5. Smyth EC, Lagergren J, Fitzgerald RC, Lordick F, Shah MA, Lagergren P and Cunningham D: Oesophageal cancer. Nat Rev Dis Primers 3: 17048, 2017.

6. Burki TK: Definitions of oesophageal cancer. Lancet Oncol 18: e71, 2017.

7. Nakajima $\mathrm{M}$ and Kato H: Treatment options for esophageal squamous cell carcinoma. Expert Opin Pharmacother 14: 1345-1354, 2013.

8. Clark MB, Johnston RL, Inostroza-Ponta M, Fox AH, Fortini E, Moscato P, Dinger ME and Mattick JS: Genome-wide analysis of long noncoding RNA stability. Genome Res 22: 885-898, 2012.

9. Tani H, Mizutani R, Salam KA, Tano K, Ijiri K, Ai W, Isogai T, Suzuki Y and Akimitsu N: Genome-wide determination of RNA stability reveals hundreds of short-lived noncoding transcripts in mammals. Genome Res 22: 947-956, 2012.

10. Bhan A, Soleimani M and Mandal SS: Long noncoding RNA and cancer: A new paradigm. Cancer Res 77: 3965, 2017.

11. Hon CC, Ramilowski JA, Harshbarger J, Bertin N, Rackham OJ, Gough J, Denisenko E, Schmeier S, Poulsen TM, Severin J, et al: An atlas of human long non-coding RNAs with accurate 5' ends. Nature 543: 199-204, 2017.

12. Rao AKDM, Rajkumar T and Mani S: Perspectives of long non-coding RNAs in cancer. Mol Biol Rep 44: 203-218, 2017.

13. Lin CY and $\mathrm{Xu} \mathrm{HM}$ : Novel perspectives of long non-coding RNAs in esophageal carcinoma. Carcinogenesis 36: 1255-1262, 2015. 
14. Chen Y, Xie H, Gao Q, Zhan H, Xiao H, Zou Y, Zhang F, Liu Y and Li J: Colon cancer associated transcripts in human cancers. Biomed Pharmacother 94: 531-540, 2017.

15. Xin Y, Li Z, Zheng H, Chan MTV and Ka Kei Wu W: CCAT2: A novel oncogenic long non-coding RNA in human cancers. Cell Prolif 50: 2017.

16. Zhang X, Xu Y, He C, Guo X, Zhang J, He C, Zhang L, Kong M, Chen B and Zhu C: Elevated expression of CCAT2 is associated with poor prognosis in esophageal squamous cell carcinoma. J Surg Oncol 111: 834-839, 2015.

17. Wang J, Qiu M, Xu Y, Li M, Dong G, Mao Q, Yin R and Xu L: Long noncoding RNA CCAT2 correlates with smoking in esophageal squamous cell carcinoma. Tumour Biol 36: 5523-5528, 2015.

18. Yu Y, Nangia-Makker P, Farhana L and Majumdar APN: A novel mechanism of lncRNA and miRNA interaction: CCAT2 regulates miR-145 expression by suppressing its maturation process in colon cancer cells. Mol Cancer 16: 155, 2017.

19. Yang P, Yang Y, An W, Xu J,Zhang G, Jie J and Zhang Q: The long noncoding RNA-ROR promotes the resistance of radiotherapy for human colorectal cancer cells by targeting the p53/miR-145 pathway. J Gastroenterol Hepatol 32: 837, 2017.

20. Xu Q, Liu LZ, Qian X, Chen Q, Jiang Y, Li D, Lai L and Jiang BH: MiR-145 directly targets p70S6K1 in cancer cells to inhibit tumor growth and angiogenesis. Nucleic Acids Res 40: 761-774, 2012

21. Tao J, Zhang J, Ling Y, McCall CE and Liu TF: Mitochondrial sirtuin 4 resolves immune tolerance in monocytes by rebalancing glycolysis and glucose oxidation homeostasis. Front Immunol 9: 419,2018

22. Livak KJ and Schmittgen TD: Analysis of relative gene expression data using real-time quantitative PCR and the 2(-Delta Delta C(T)) method. Methods 25: 402-408, 2001.

23. Kusaba $\mathrm{H}$ and Saijo N: A summary report of response evaluation criteria in solid tumors (RECIST criteria). Gan To Kagaku Ryoho 27: 1-5, 2000 (In Japanese).

24. Wu L, Jin L, Zhang W and Zhang L: Roles of long non-coding RNA CCAT2 in cervical cancer cell growth and apoptosis. Med Sci Monit 22: 875-879, 2016.

25. Zhou N, Si Z, Li T, Chen G, Zhang Z and Qi H: Long non-coding RNA CCAT2 functions as an oncogene in hepatocellular carcinoma, regulating cellular proliferation, migration and apoptosis. Oncol Lett 12: 132-138, 2016.

26. Campbell NP and Villaflor VM: Neoadjuvant treatment of esophageal cancer. World J Gastroenterol 16: 3793-3803, 2010.

27. Lordick F, Hölscher AH, Haustermans K and Wittekind C: Multimodal treatment of esophageal cancer. Langenbecks Arch Surg 398: 177-187, 2013.

28. Sihvo E, Anttonen A and Huuhtanen R: Treatment of esophageal cancer. Duodecim 130: 565-572, 2014 (In Finnish).

29. Leszczynska KB, Foskolou IP, Abraham AG, Anbalagan S Tellier C, Haider S, Span PN, O'Neill EE, Buffa FM and Hammond EM: Hypoxia-induced p53 modulates both apoptosis and radiosensitivity via AKT. J Clin Invest 125: 2385-2398, 2015.
30. Olive PL and Durand RE: Apoptosis: An indicator of radiosensitivity in vitro? Int J Radiat Biol 71: 695-707, 1997.

31. Ye C, Sun NX, Ma Y, Zhao Q, Zhang Q, Xu C, Wang SB, Sun SH, Wang F and Li W: MicroRNA-145 contributes to enhancing radiosensitivity of cervical cancer cells. FEBS Lett 589: 702-709, 2015.

32. Gong P, Zhang T, He D and Hsieh JT: MicroRNA-145 modulates tumor sensitivity to radiation in prostate cancer. Radiat Res 184: 630-638, 2015

33. Chen Y, Shen Z, Zhi Y, Zhou H, Zhang K, Wang T, Feng B, Chen Y, Song H, Wang R and Chu X: Long non-coding RNA ROR promotes radioresistance in hepatocelluar carcinoma cells by acting as a ceRNA for microRNA-145 to regulate RAD18 expression. Arch Biochem Biophys 645: 117-125, 2018.

34. Zhao P, Meng Q, Liu LZ, You YP, Liu N and Jiang BH: Regulation of survivin by PI3K/Akt/p70S6K1 pathway. Biochem Biophys Res Commun 395: 219-224, 2010.

35. Chai X, Sun D, Han Q, Yi L, Wu Y and Liu X: Hypoxia induces pulmonary arterial fibroblast proliferation, migration, differentiation and vascular remodeling via the PI3K/Akt/p70S6K signaling pathway. Int J Mol Med 41: 2461-2472, 2018.

36. Weichselbaum RR, Liang H, Deng L and Fu YX: Radiotherapy and immunotherapy: A beneficial liaison? Nat Rev Clin Oncol 14: 365-379, 2017.

37. Krause M, Dubrovska A, Linge A and Baumann M: Cancer stem cells: Radioresistance, prediction of radiotherapy outcome and specific targets for combined treatments. Adv Drug Deliv Rev 109: 63-73, 2017.

38. Ma J, Li Y, Wu M and Li X: Oxidative stress-mediated $\mathrm{p} 53 / \mathrm{p} 21^{\text {WAF1/CIP1 }}$ pathway may be involved in microcystin-LR-induced cytotoxicity in HepG2 cells. Chemosphere 194: 773-783, 2018.

39. Ma J, Chen X, Xin G and Li X: Chronic exposure to the ionic liquid $\left[\mathrm{C}_{8} \mathrm{mim}\right] \mathrm{Br}$ induces inflammation in silver carp spleen: Involvement of oxidative stress-mediated p38MAPK/NF- $\kappa \mathrm{B}$ signalling and microRNAs. Fish Shellfish Immunol 84: 627-638, 2019.

40. Kim EM, Jung CH, Kim J, Hwang SG, Park J and Um HD: The p53/p21 complex regulates cancer cell invasion and apoptosis by targeting Bcl-2 family proteins. Cancer Res 77: 3092-3100, 2017.

41. Hernandez Borrero LJ, Sikder R, Lulla A, Gokare P, Del Valle PR, Tian X, Zhang S, Abbosh PH and El-Deiry WS: Bcl-2 protein targeting by the p53/p21 complex-letter. Cancer Res 78: 2770-2771, 2018.

42. Liu X, Yu H, Cai H and Wang Y: Expression of CD24, p21, p53, and c-myc in alpha-fetoprotein-producing gastric cancer: Correlation with clinicopathologic characteristics and survival. J Surg Oncol 109: 859-864, 2014.

43. Hermeking H, Funk JO, Reichert M, Ellwart JW and Eick D: Abrogation of p53-induced cell cycle arrest by c-Myc: Evidence for an inhibitor of p21WAF1/CIP1/SDI1. Oncogene 11: 1409-1415, 1995. 